\title{
Cooperation between NGOs and Government in Public Crisis Management in China: Contexts, Practical Plights and Solutions
}

\author{
Jiayi Tang \\ Xinhua College \\ Sun Yat-Sen University \\ Guangzhou, China
}

\begin{abstract}
In recent years, China has been faced with more and more severe public crisis such as earthquake and largescale rainstorm in many cities and it becomes a more challenging issue for Chinese government to cope with these high-frequency public crises. With the rise and development concept of "civil society" in many countries, China now has a growing number of non-government organizations (NGOs) which emerge to participate in social affairs including public crisis and the cooperation and coordination between these NGOs and the government is a new topic for the public administration in China's political system. In this paper I explore the contexts and practical plights of interaction and coordination between NGOs and government in China through relevant theories on public administration and via the Sichuan Earthquake case in $\mathbf{2 0 0 8}$ and after that analysis I propose some countermeasures and possible ways of enhancing and promoting the "NGO-government" cooperation in China's public crisis management under current social environment in China.
\end{abstract}

Keywords-public crisis; NGOs; government; public management

\section{INTRODUCTION}

Over the past decade, there have been a rising number of public crises, including the natural disasters and social incidents in China and it is more and more frequent to witness public crisis. At the same time, harms and dangers brought by these public crises are increased and public crises are having a larger scale of impacts on both the society and the general public. Actually this is not just the case in China, with the development and globalization around the globe, recently we have seen more and more public crises I many countries and it is reasonable to assume that such tendency would be continued in future because of further development and deteriorating environments. Many countries are making efforts to find better solutions and strategies in preventing and tackling with public crises in order to be better equipped with coping with public crises. It goes without saying that reforms in public crisis management is a new and crucial area for bureaucracies to pay attention to when governments are trying to provide better service to the society.

Currently China is undergoing a social transformation period in its development and management model and this is also a period in which public crisis is more common and frequent. (Peter Hays Gries \& Stanley Rosen, 2012) Since last millennium, there have been a great number of public crises China, to name a few, the SARS (Severe Acute Respiratory Syndromes) in 2003 which has caused death not only in mainland China but in Hong Kong, Taiwan, Macau and even other countries like Vietnam and the U.S ${ }^{\left[{ }^{1}\right]}$, the 2008 Sichuan Earthquake which has taken more than 60 thousand deaths in China ${ }^{[2]}$ and the Urumchi Riot in 2009 which has triggered domestic and overseas social protest to the Chinese government. It is a big challenge for Chinese government to cope with these large-scale public crises while facing with so many other internal and external problems which impacts the safety and stability of the country and it is a real and important test for the Chinese government to tackle with public crisis as this would greatly influence both domestic and overseas judgments to the Chinese government.

It is obvious and apparent that in a public crisis, government is the dominant power in managing the crisis as for one thing, government is provider of public service as well as the manager of public affairs and for another thing, government has unparalleled resources, including personnel, materials and funds which are all vital to cope with these crisis issues. Therefore, government is undoubtedly one of the most important leading roles in public crisis management. Nevertheless, it is far from enough to have just government as the acting role in public crisis management in the current environment which is full of potential crisis. As public crisis is always abrupt and spreading, it is not reasonable and practical to rely merely on government to cope with the crises. It is believed that once a public unexpected issue is going out of socially bearing capability, it would disturb the social order and decreases the efficiency of government's work. (Christopher Hood, 1991) That is to say, other nongovernment organizations have to be mobilized in order to ensure that the social crisis could be handled in a relatively ideal way. It is now a common practice in many countries

\footnotetext{
${ }^{1}$ Timeline of the SARS Outbreak.

http://en.wikipedia.org/wiki/Timeline_of_the_SARS_outbreak ${ }^{2} 2008$ Sichuan Earthquake.

http://en.wikipedia.org/wiki/2008_Sichuan_earthquake
} 
that "omnipotent government" is transforming to a "limited government".

Non-government organizations (NGOs) are important components of a civil society in many countries and NGOs are always indispensable power in public issues and affairs including public crises in many cases. It becomes increasingly common to see NGOs play as an active role in all kinds of unexpected issues and NGOs are becoming more and more helpful in tackling with crisis issues. For instance, according to the National Response Plan (NRP) in the U.S., NGOs are supposed to cooperate and coordinate with the government to provide help and rescue when there is no other source of recourse and assistance and there is a clear cooperation framework between these NGOs and the government departments in the U.S ${ }^{[3]}$. In Japan, NGOs have long been a participant in public crisis management and a typical case is the Hhanshin Earthquake in 1995-in this case, the first organization which came to the disaster area is not the government, but the NGOs ${ }^{[4]}$, and from then on, NGOs have been promoted in Japan in crisis issues and this has been a successful case for many countries to attachment importance to the role of NGOs in public crisis.

Chinese government and the society have recognized the importance and values of NGOs and there are approximately half million NGOs in China in all areas up to 2012, ${ }^{[5]}$ including poverty, illness, women's rights and so on so forth. However, the inconsistent reality is when there is a public crisis in China, it is rare to find powerful and strong cooperation between these NGOs and governments and usually these two types of important power in public crisis are more likely to act respectively and there is no strong connection which cause a waste of social resources and decreases the management efficiency to a great extent.

In this paper, I am looking the relevant issues about the cooperation and interaction between the governments and the NGOs from three aspects--(1) the contexts: through some theories and experiences in other countries, I am exploring why it is important to promote coordination between NGOs and government and why it is possible to set up such cooperative relationship; (2) practical plights: from the Sichuan Earthquake case in 2008 I analyze some restriction of NGOs' participation in China's public crisis management system and mechanism; (3) solutions: through the first two parts of research, I try to propose some possible measures to promote and enhance the interaction and cooperation between NGOs and government in China's public crisis management.

\footnotetext{
${ }^{3}$ NGOs and Government: a New Basis for Cooperation.

https://www.chinadialogue.net/article/2049-NGOs-and-government-a-newbasis-for-cooperation

${ }^{4}$ Japan's NGO Activities and the Public Support System.

http://www.gdrc.org/ngo/jp-ngoactivities.html

${ }^{5}$ Number of NGOs in China grows to nearly 500,000.

http://www.chinadaily.com.cn/china/2012-03/20/content_14875389.htm
}

\section{ACTUAL Plights: EXISTING PROBLEMS "NGOS - GOVERNMENT" COOPERATION}

Now take a deeper look at China's current situation of "NGOs-Government" cooperative relationship in public crisis management and here I will use the 2008 Sichuan Earthquake as an example and this is a typical case for learning about the relations between "NGOs-Government" for several reasons: (1) although the presence of NGO is not new and there has been plenty of NGOs since 1990s in China ${ }^{[6]}$, in the Sichuan Earthquake thousands of NGOs in China percolated unprecedented actively in the rescue and assistance and it was perceived that this is a great improvement in China's NGOs role in public affairs by many experts ${ }^{[7]} ;(2)$ according to a report published by Peking University, 2008 could be viewed as The first year of China Civil Society and also The First Year of China Volunteer $^{[8]}$. It is widely believed that NGOs as the players in the third sector in China has shown a great responsibility to the society and they received widespread praise for their participation in Sichuan Earthquake's rescue work; (3) however, as a trial and beginning of "NGOs-Government" cooperation and interaction in China's public crisis management, there are still many conundrums and plights for both Chinese government and Chinese NGOs to resolve before setting up a real effective and efficient relations of cooperation in crisis management in China's public administrative situation and this is also a reason why I use the Sichuan Earthquake in 2008 as a case to study the actual cooperative relations between NGOs and government in China.

\section{A. Validity in NGO's Identity - Lack of Qualification in Participation in Crisis Management}

A most prominent problem exiting in China's "NGOsGovernment" cooperation in crisis management is there is no relevant legal support for NGOs to gain lawful validity in identity in participation. ${ }^{[9]}$ In China, there is not yet a mature management and regulation system for the management and regulation of NGOs or any specific law which explains the role of NGOs in public crisis management. (Ni Chen, 2009) As a result, some grassroots NGOs could not fully act in the rescue work in a public crisis as they do not have a clear legal identity which supports their act in participation. Here I use two contrast NGOs cases in Sichuan Earthquake to illustrate the significance of a valid identity in crisis management and the current situation in China's crisis management system.

There are several government-supported NGOs in China, such as the Red Cross Society of China, China Foundation

\footnotetext{
${ }^{6} \mathrm{Xu}$ Ying and Zhao Litao. China's Rapid Growing Non-Governmental Organizations. [OL]. http://www.eai.nus.edu.sg/BB514.pdf

${ }^{7}$ An Emerging Civil Society: The Impact of the 2008 Sichuan Earthquake on Grassroots Civic Associations in China.

http://www.chinadevelopmentbrief.cn/?p=465

8 2008: the First Year of China Volunteer. http://politics.people.com.cn/GB/1026/7336201.html

${ }^{9}$ On the Eve of the Third Plenum, Are We Seeing a Depoliticization of the NGO Sector? http://ngochina.blogspot.ca/2013/11/on-eve-of-third-plenumare-we-seeing.html
} 
for Poverty Alleviation and China Charity Federation. Although legally these NGOs are independent organizations which are not inside the administrative system in China, in practice they are still in strong connection with local governments and media which provides significant support for them to attract members to join and to launch fundraising events. It is reported that China Foundation for Poverty Alleviation has raised nearly 76 hundred million RMB in half a year after the Sichuan Earthquake ${ }^{\left[{ }^{10}\right]}$ and its legal status in Chinese NGOs systems is perceived a significant reason for its efficiency in acting in this crisis ${ }^{[11]}$. On the contrary, there are many grassroots NGOs which have the strong willing to take part in, but could not fully act to assist the local residents in the earthquake as they do not have relevant legal validity in its identity or permission by governments. In Sichuan Earthquake, many grassroots which have specialized and professional backgrounds tried to help the rescue and recovery work in the local areas but these grassroots NGOs, which are not developed from the Chinese administrative system or as branches of international NGOs like Oxfam, do not have the qualification to act and this actually hinders the efficiency of cooperation between NGOs and government as many grassroots NGOs actually could not come into play in public crisis issues.

Lacking of legal regulation and management in grassroots NGOs is an outstanding issue and problem in the cooperative relationship between NGOs and government in China. ${ }^{[12]}$ Without a legitimate qualification admitted by government and relevant departments, NGOs could not act and play as a partner with government, nor could it obtain trust from the citizens or media and this would greatly hinders the development and function of NGOs, especially grassroots NGOs in public crisis management.

\section{B. Deficient Communication-Unreasonable Distribution of Resources in Rescue}

Good communication and sufficient information is vital in any operation in public crisis management. Because of the destructive and urgent features, fast and close communication and coordination between different organizations becomes more important and vital. However, in the Sichuan Earthquake, there are still many drawbacks in the communication mechanism between NGOs and government in order to improve the efficiency of resource distribution in a crisis management issue: (1) In the Sichuan Earthquake, almost all assisting actions outside the governmental administrative system are voluntary and initiative which are organized by NGOs. However, there have been prominent conflicts between ideal and reality in

\footnotetext{
${ }^{10}$ The China Foundation for Poverty Alleviation Opens Its Account Books on the Third Anniversary of the Wenchuan Earthquake.

http://www.chinadevelopmentbrief.cn/?p=807

11 Catalyzing Social Investment in China. [OL].

http://www.bsr.org/reports/Catalyzing_Social_Investment_in_China_BSR

CiYuan_November_2011.pdf

${ }^{12}$ The 2008 Sichuan Earthquake and China's NGOs.

http://ngochina.blogspot.ca/2010/02/2008-sichuan-earthquake-and-chinasngos.html
}

the rescue activities. Many media have reported a situation that "many grassroots NGOs rushed to the affected areas in Sichuan with plenty of resources and a large number of volunteers, however, right after they reached the disaster-hit area they found that roads have been blocked and they could not even get into the local areas" $\left.{ }^{13}\right]$. Under such circumstance, grassroots NGOs and their volunteers could not really help to a great extent and this has greatly reduces people's enthusiasm in further participation in the rescue work. (2) Another aspect of such deficient communication between NGOs and government is, NGOs and their personnel have no idea about where to go or do what to help. After the Sichuan Earthquake, some media interviewed volunteers who have taken part in the rescue work in the crisis and many of them viewed perceive "what to do for the disaster-hit areas" and "which areas need volunteers" as the most confusing questions for them when they tried to participate. ${ }^{\left[{ }^{14}\right]}$ Usually when faced with a severe crisis in the society, Chinese people have great passion to help and this is called "If one part of China has problems, help should come from eight other directions" (Yifangyounan, Bafangzhiyuan) in Chinese. Nevertheless, without proper guidance from government to these NGOs and volunteers, it is always a waste of both time and resources and this is a reason for the later disorder in recovery work in Sichuan-because there is not sufficient communication between local government and NGOs, many NGOs tried to be the first one to help rebuild a school in some areas while in other areas, no NGO participated or paid attention to the reconstruct work ${ }^{[15]}$.

NGOs are usually willing to offer their help in crisis issues but without a proper communication mechanism between local government and these NGOs, it always gets just the opposite. Local government in a crisis has all the first-hand information about the crisis situation which is hardly obtained by the NGOs quickly, such as where needs personnel, what kind of recourses are in short and in which area needs assistance, etc. without proper communication about these issues, NGOs might have not clear ideas about where to put their recourse in and sometimes this would lead to a low efficiency as well as overlap in resources distribution, which is negative in crisis management.

\section{Restricted Culture-Low Social Recognition of "NGOs- Government" Cooperation}

Social identification and recognition is a fundamental support and basis for NGOs to cooperate with government in public crisis issues as without such social support, actually NGOs could seldom play a part in any aspect of crisis management. It is a common trend that in future, both NGOs and government are an indispensable component in crisis management in the society and in order to optimize the efficiency of resources distribution and utilization as well as

\footnotetext{
${ }^{13}$ A Research on the Role of NGOs in Rescue and Recovery in Wenchuan Earthquake. http://blog.sina.com.cn/s/blog_733ba5590101fkls.html ${ }^{14}$ From Wenchuan to Yushu: the Growth of NGOs in China. http://scitech.people.com.cn/GB/11452730.html

${ }^{15}$ Zhu Jiangang. Responsibility, Action and Cooperation-NGOs' Participation in Wenchuan Earthquake. [M]. Peking University Press. 2009:60-66
} 
the benefits of citizens, NGOs and government should establish a long-term cooperative and coordinative relationship and mechanism in crisis management system. In Chine, however, there is still not widespread promotion and introduction about NGOs thus most NGOs do not have high recognition among either citizens or the society, except for some traditional NGOs which are originating from the administrative system itself, like China Foundation for Poverty Alleviation. ${ }^{[16]}$ Suppose the recipients of assistance in a public crisis - the citizens - do not have believe in the cooperation between NGOs and government or do not have a clear idea about the functions and role of NGOs, it is hard for both NGOs and government to ensure a good cooperation in a crisis event.

There was an example in Sichuan Earthquake to this point: after this severe disaster, there were tens of thousands donations which amount to more than two billion RMB from all over the country to the Sichuan Red Cross branch but as there only 17 fiscal personnel in the Red Cross, the NGO found it hard to handle such great amount of money with a limited number of people. The most practical and direct solution for the Red Cross at that time was to seek help from the Sichuan government and asked the financial department of local government to reserve the donations for the safety angle. ${ }^{[1]}$ However, after such managing method has been reported by media, citizens around China doubted about such arrangement and decreased the donation to Red Cross as they were afraid that their donations to the NGOs would be embezzled by the government and NGOs are just a disguise for government to improperly gaining money from citizens in a crisis ${ }^{[18]}$.

The feature of independence is one of the most important for NGOs to gain trust and recognition among the citizens and people support NGOs because of their nonprofit as well as nongovernment natures.(Chailes Chan, 1997) It is important for both NGOs and the government to guarantee two principles in cooperation in order to gain widespread recognition among citizens: first, NGOs should keep playing as an independent role in public crisis management both financially and institutionally, which is the most significant foundation for NGOs and government to build up long-term cooperative relationship; second, both government and NGOs should promote their cooperation to the society in order to popularize the idea of civil society and voluntary spirit to gain support and trust in a crisis management work. However, this is still a deficiency in the cooperation relation between NGOs and government in China's public crisis management system.

\footnotetext{
${ }^{16}$ The 2008 Sichuan Earthquake and China's NGOs.

http://ngochina.blogspot.ca/2010/02/2008-sichuan-earthquake-and-chinasngos.html

${ }^{17}$ Disaster Shows Faith in China's Red Cross Badly Shaken. https://chinadigitaltimes.net/2013/04/disaster-shows-faith-in-chinas-redcross-badly-shaken/

${ }^{18}$ Same reference as " 18 "
}

\section{SOLUTIONS: TO IMPROVE "NGOS-GOVERNMENT" COOPERATION IN CRISIS MANAGEMENT}

Based on the previous analysis in this paper, and drawing from the experience from other countries where NGOs are in a highly-efficient cooperative relation with government, I am proposing some possible countermeasures to the exiting problems in the "NGOs-Government" cooperation in China's public crisis management and administration system. In general, there are three suggestions which are corresponding to the current drawbacks which have been discussed above:

\section{A. Legal and Institutionalized Support-Guidance of Responsibility and Power}

It has been pointed above that currently there is few specialized law or regulation upon the management of NGOs in China and this leads to the invalidity in NGO's identity, which hinders NGOs' participation in a crisis rescue work to a great extent because of no legal status, especially for the grassroots NGOs which are organized by the general public groups. ${ }^{\left[{ }^{19}\right]}$ Also, since relevant law and institution is absent, sometimes it is hard to monitor NGO's work in a crisis assistance work and this would not only decreases the efficiency of resources distribution, but also causes confuse and distrust to the cooperation between NGOs and government among the citizens and public, as people have no clear idea about what are the respective responsibilities and power in a crisis issue and they do not know the real mechanism of such cooperative relationship, leading to hesitation when thinking of donate or join some organizations. From the angle of legal and institutional support in order to ensure the cooperation between government and the NGOs, two main issues are urgent and necessary for China to conduct some reforms in its crisis management system and mechanism:

First, it is necessary to set up a registration institution for NGOs in order to provide valid identity for NGOs so that these organizations could legally join the management work in crisis issues as without such status in law, it is almost impossible for them to gain trust or support by the majority of citizens or the attention from media. Currently there are a small number of NGOs like the Red Cross Society of China and China Foundation for Poverty Alleviation which are in strong connection with government departments and these NGOs are the dominant power in China's existing "NGOGovernment" cooperation in crisis management system, but there are a majority of grassroots NGOs are not "legally" presenting in the civil society in China just because there is no mature registration institution therefore in order to expand the influence of these NGOs and provide legal support for these grassroots NGOs, it is requisite to build up a complete, formal and systematic framework of access system for NGOs under related law and regulation so that a large number of grassroots NGOs could also obtain relevant policy

\footnotetext{
${ }^{19}$ The 2008 Sichuan Earthquake and China's NGOs. http://ngochina.blogspot.ca/2010/02/2008-sichuan-earthquake-and-chinasngos.html
} 
support and resources share with government in crisis management work.

Second, from developed countries' experience, it is important to provide a sound legal system which supports and regulates the mechanism of social participation. For example, there is a mature law system, including National Security Act (1947), Disaster Relief Act (1950), The Homeland Security Act (2002) etc, in public crisis management in the U.S. and according to the revised National Response Plan in 2005, citizens, communities and other NGOs could participate in crisis management under certain regulation ${ }^{[20}$. As guarantee and protection of cooperation and participation for NGOs in crisis management, relevant law which sets standard for the responsibility of NGOs and government in a crisis issue should be set out otherwise it is almost impossible to carry out any cooperative programs in crisis management.

\section{B. Information and Communication Mechanism- Improvement in Management Efficiency}

The significance of good communication and sufficient information needs no further explanation. However, as the complication of mechanism in China's administration system and the huge number of emerging NGOs in China since 1990 s, there is not yet a systematic communicative mechanism between NGOs and government in crisis managements system, which is indispensable and necessary to ensure high efficiency in rescue work in a crisis. Smooth information communication channel should be established to enhance the efficiency of information transfer within NGOs and government and an information-sharing platform and system is required in order that all crisis-related information and message could be integrated and collected, making sure that both NGOs and government could have instant information about the crisis issues and then allocate personnel and material resources appropriately, which would apparently enhance the effects for management in a public crisis. Just as the case in Sichuan Earthquake which has been talked above, as without such smooth and updated information for NGOs, these organizations and their volunteers could not have any idea about which area to assist in and such operation in a crisis is not helpful and effective.

Taking the German crisis information system as an example, information communication in public crisis is conducted with two subsystems: one is for general public to get all kinds of information related with crisis issues, in order to provide guidance about how to enhance the sense crisis and what to do when faced with a real crisis situation; another system which contains information about crisis situation in a geographic formation, is for authorized organizations like some NGOs and other bureaucracies in order to provide helpful information for these organizations and departments to make "proper" decision in crisis management work. ${ }^{\left[{ }^{2}\right]}$ For China, it is necessary to set up

\footnotetext{
${ }^{20}$ National Response Framework. http://www.fema.gov/national-responseframework

${ }^{21}$ Crisis Management Systems in Germany--A Status Report about the

Current Functions and Developments of Private and Public Crisis
}

related websites or information system for both citizens and NGOs to get access to crisis-related news so that for one thing, social panic and rumor might be relieved or decreased and citizens have a better idea about the latest news about the crisis situation before getting further preparation for the crisis issues; for another, NGOs could gather more real-time information so that their assistance in crisis rescue could be more effective and less resource-consuming.

\section{Social Promotion-Publicizing the "NGO-Government" Cooperation Concept among Society}

In Sichuan Earthquake's case, there was an embarrassing situation which displays the urgent requirement of social promotion for the "NGOs-Government" cooperation in China as mentioned above: when NGOs (the Red Cross) could not handle the huge amount of donation from the public and seeks help from the government, citizens felt doubtful and suspicious about the relationship between NGOs and government and they were less willing to donate as they were afraid their donation might be obtained by the government instead of the affected people. ${ }^{[2]}$ NGOs as the third-party of the modern-day society, has become an indispensable managing power in many civil society in developed countries. Social Governance is a significant concept according to the Self-Governance Theory and NGOs/NPOs are crucial carriers and the main components of participants in order to fulfill social governance. (Judith R. Saidel, 1991) Even when China has set up a systematic institution about regulating the responsibility and power of NGOs and government in crisis management, it is also crucial to publicize and promote such cooperative relationship among the society to gain more trust from the citizens towards the interaction and coordination between NGOs and government. It must be noted that one important reason why NGOs could obtain support and trust from the citizens it because of its non-profit and nongovernment nature, which attracts the citizens as they perceive these organizations are for public-good benefits and neutral. (Lester M. Salamon, 1987) So for NGOs, it is necessary to bear in mind that while they should run under certain regulation set up by the government for a cooperative mechanism, it is always significant to keep independence in both financial and institutional aspect so that NGOs would be influenced and controlled by government; for government, it is required to provide proper guidance and regulation for these NGOs to create a more well-organized and ordered participation environments in crisis management and at the same time, allow them to run independently with respective responsibility; for both of them, lastly, to promote the concept and benefits of "NGOs-Government" cooperation and coordination is also necessary otherwise people and citizens outside the government and NGOs might not trust the NOGs and without public's support, it is almost impossible for any NGO to run, play or act fully in public affairs.

Management Systems in Germany.[OL].

http://www.iscramlive.org/ISCRAM2012/proceedings/282.pdf

${ }_{22}$ Thousands of Thumbs Down for Chinese Red Cross.

http://blogs.wsj.com/chinarealtime/2013/04/20/earthquake-in-sichuan-

charity-organization-has-china-seeing-red/ 


\section{CONCLUSION}

Although unlike other developed countries which has a long history and strong tradition of grassroots NGOs' participation in public affairs, including the management of public crisis issues, China has witnessed a fast-pace development in its NGOs over the past two decades since 1990s and now NGOs in growing numbers are still emerging and becoming part of the civil society in China's public administration and management. As China is on a period of social reforming and transition, and the environment problems have been deteriorated as the high-speed economic development over the past 30 years, now China has entered an era of frequent public crisis, including natural disasters and social incidents and it has become more challenging and urgent for China to handle and tackle with these public crisis issues in order to ensure the social safety and stability.

There are many reasons why China has to pay attention to the cooperation between government and NGOs when faced with public crisis. Just as many countries else, Chinese government has some weaknesses in coping with public crisis although it has the strongest power in distributing efficiency in a crisis and a special situation in China is, nowadays the relationship between citizens and the government is being increasingly tight and sometimes public just distrusts the government, even in a crisis case. On the other hand, NGOs, with specialized backgrounds and experience in crisis rescue and assistance, could play a role in crisis management and help cope with these crisis issues. Moreover, from the angle of both theory and practice, it is necessary and practical to launch further cooperative relationship between NGOs and government in crisis management as it is not only a form of civil society governance but also successful experience from many other countries. In addition, establishing a relationship as cooperative, coordinative and interactive is a "win-win-win" mechanism, which is beneficial for government, NGOs and also for the general public in China.

In Sichuan Earthquake in 2008 in China, there had been an unprecedented high participation of NGOs in crisis management in China and it could be seemed as a start and trail for cooperation between Chinese related governments and NGOs in crisis rescue and assistance. Sichuan Earthquake displays a great improvement in China's civil governance; however, when looking at the case with a deeper angle, we could still find that there exist quite a few weaknesses in the cooperative mechanism between NGOs and government in China's public crisis management system. Just take three of them as examples: first, among the 300 NGOs which had taken part in the rescue in Sichuan Earthquake, only a limited number of them had government permission and most of the rest could not gain any government support or valid identity, which greatly hindered the efficiency of these NGOs and decreased volunteer's enthusiasms from these organizations; Second, lacking sufficient communication between NGOs and government, in Sichuan Earthquake we could see a phenomenon of lesseffective and unreasonable distribution of resources during the rescue work, and sometimes the participation of NGOs is disordered as they did not ha clear guidance and updated information about the crisis situation; Lastly, the concept and idea of cooperation between NGOs and government is still not widely promoted among the public in China, which led to distrust and doubt among citizens while NGOs tried to seek help from the government to handle the donation to the affected areas and people.

It is necessary for both NGOs and government in China to take some measures in order to improve the efficiency and enhance the quality of cooperation work in crisis management. Corresponding to the previous problems which have been pointed out above, sever suggestions have been made to tackle with the current awkward situations in China's "NGOs-Government" cooperation in crisis management. To solve the problem that there is no valid identity in some grassroots NGOs, it is necessary to set up some regulations and institutions for NGOs' registration and related law should be made to regulate the responsibilities and power of both government and NGOs in crisis issues. What's more, establishing some effective communicative channel is also significant as this could help prevent improve the efficiency of resource distribution when NGOs and governments participate together in rescue work in a crisis. Also, it is important for both NOGs and government to promote the idea and concept of cooperation between them among the society so that public could have a better understanding about "NGOs-Government" cooperative and coordinative relations while NGOs are still a nongovernment sector in the society to role for the public good.

\section{REFERENCES}

[1] Peter Hays Gries and Stanley Rosen. State and Society in 21s Century China: Crisis, Contention and Legitimation. [M]. Routledge, 2012

[2] Christopher Hood. A Public Management for All Season? [J]. Public Administration, 1991, 69(1):3-19

[3] Jennifer M. Costonl. A Model and Typology of Government Nonprofit Organization Relationship [J]. Nonprofit and Voluntary Sector Quarterly, 1998 27(3):358-382

[4] Adil Najam. Understanding the Third Sector: Revisiting the Prince, the Merchant, and the Citizen. [J]. Nonprofit Management and Leadership, 1996, 7(2): 203-219

[5] Jesse D. Lecy and David M. Van Slyke. Alternative Models of Government and Nonprofit Sector Relations: Theories and International Perspective [J]. Public Administration Research and Theory, 2013, 23(1):189-214

[6] Zixue Tai and Tao Sun. Media dependencies in a changing media environment: the case of the 2003 SARS epidemic in China. [J]. New Media \& Society. 2007, 9(6):987-1009

[7] Elinor Ostrom, James Walkera and Roy Gardner. Covenants with and without a Sword: Self-Governance Is Possible. [J]. American Political Science Review. 1992, 86(2):404-417

[8] Eran Vigoda. From Responsiveness to Collaboration: Governance, Citizens, and the Next Generation of Public Administration. [J]. Public Administration Review. 2002, 62(5):527-540

[9] Lester M. Salamon. Of Market Failure, Voluntary Failure, and ThirdParty Government: Toward a Theory of Government-Nonprofit Relations in the Modern Welfare State. [J]. Nonprofit and Voluntary Sector Quarterly. 1987, 16 (1-2): 29-49

[10] Isabel Maria Macedo and José Carlos Pinho. The Relationship between Resource Dependence and Market Orientation: The Specific Case of Non-Profit Organizations. [J]. European Journal of Marketing. 2006, 40 (5-6):533 - 553 
[11] Ni Chen. Institutionalizing Public Relations: A Case Study of Chinese Government Crisis Communication on the 2008 Sichuan Earthquake. [J]. Public Relations.2009, 35(3):187-198

[12] Judith R. Saidel. Resource Interdependence: the Relationship between State Agencies and Nonprofit Organizations. [J]. Public Administration Review. 1991, 51 (6):543-553

[13] Zhang Juntao and Cao Yuling. Regional Public Administration under the Framework of Collaborative Governance. [J]. Management Science and Engineering, 2010:1823-1830

[14] Zhu Jiangang. Responsibility, Action and Cooperation-NGOs' Participation in Wenchuan Earthquake. [M]. Peking University Press. 2009:60-66

[15] Chailes Chan. The 3 C's of NGO-Government Relations: Confrontation, Complementarity, and Collaboration. [M] .Boston University, 1997.

[16] Dennis R. Young. Alternative Models of Government-Nonprofit Sector Relations: Theoretical and International Perspectives. [J]. Nonprofit and Voluntary Sector Quarterly, 2000, 29(1):149-172

[17] Adil Najam. The Four-C's of Third Sector-Government Relations: Cooperation, Confrontation, Complementarity, and Cooptation. [J]. Nonprofit Management and Leadership, 2000, 10(4):375-396

[18] Stein Kuhnle and Per Selle Government and Voluntary Organizations: A Relational Perspective. [J]. Contemporary Sociology, 1994, 23(4):.585-586

[19] Timeline of the SARS Outbreak http://en.wikipedia.org/wiki/Timeline_of_the_SARS_outbreak

[20] 2008 Sichuan Earthquake. http://en.wikipedia.org/wiki/2008_Sichuan_earthquake

[21] NGOs and Government: a New Basis for Cooperation https://www.chinadialogue.net/article/2049-NGOs-and-governmenta-new-basis-for-cooperation

[22] Japan's NGO Activities and the Public Support System. http://www.gdrc.org/ngo/jp-ngoactivities.html

[23] Number of NGOs in China grows to nearly 500,000. http://www.chinadaily.com.cn/china/201203/20/content_14875389.htm

[24] NGO Security. http://www.interaction.org/work/security

[25] China's Rapid Growing Non-Governmental Organizations. http://www.eai.nus.edu.sg/BB514.pdf

[26] An Emerging Civil Society: The Impact of the 2008 Sichuan Earthquake on Grassroots Civic Associations in China. http://www.chinadevelopmentbrief.cn/?p=465

[27] 2008: the First Year of China Volunteer. http://politics.people.com.cn/GB/1026/7336201.html

[28] On the Eve of the Third Plenum, Are We Seeing a Depoliticization of the NGO Sector? http://ngochina.blogspot.ca/2013/11/on-eve-ofthird-plenum-are-we-seeing.html

[29] The China Foundation for Poverty Alleviation Opens Its Account Books on the Third Anniversary of the Wenchuan Earthquake. http://www.chinadevelopmentbrief.cn/?p=807

[30] Catalyzing Social Investment in China. [OL] http://www.bsr.org/reports/Catalyzing_Social_Investment_in_China_ BSR_CiYuan_November_2011.pdf

[31] The 2008 Sichuan Earthquake and China's NGOs. http://ngochina.blogspot.ca/2010/02/2008-sichuan-earthquake-andchinas-ngos.html

[32] A Research on the Role of NGOs in Rescue and Recovery in Wenchuan http://blog.sina.com.cn/s/blog_733ba5590101fkls.html

[33] From Wenchuan to Yushu: the Growth of NGOs in China. http://scitech.people.com.cn/GB/11452730.html

[34] Disaster Shows Faith in China's Red Cross Badly Shaken. https://chinadigitaltimes.net/2013/04/disaster-shows-faith-in-chinasred-cross-badly-shaken/

[35] National Response Framework. http://www.fema.gov/nationalresponse-framework
[36] Crisis Management Systems in Germany--A Status Report about the Current Functions and Developments of Private and Public Crisis Management Systems in Germany.[OL].

[37] http://www.iscramlive.org/ISCRAM2012/proceedings/282.pdf

[38] Thousands of Thumbs down for Chinese Red Cross http://blogs.wsj.com/chinarealtime/2013/04/20/earthquake-insichuan-charity-organization-has-china-seeing-red/ 